\title{
Coated Silver Nanoparticles Exhibit Unique Stability and Cytotoxicity in Media with Human Serum
}

\author{
Filip Kunc and David C. Kennedy* \\ Metrology, National Research Council Canada, 1200 Montreal Road, Ottawa K1A 0R6, Canada
}

^Corresponding author: Dr. David Kennedy, Metrology, National Research Council Canada, 1200 Montreal Road, Canada; Tel: 6139008065; E-mail: david.kennedy@nrc-cnrc.gc.ca

Received: September 25, 2020; Accepted: October 05, 2020; Published: October 18, 2020

\begin{abstract}
Commercially available silver nanoparticles with five different coatings were measured for stability in media supplemented with human serum (HS) to better mimic conditions that particles might be exposed to in biomedical applications. The particles were then tested for cytotoxicity and cellular uptake in two cell lines. The stability of the particles differs from what is observed in media supplemented with fetal bovine serum (FBS). There is also a change in both the cytotoxicity of the particles and their cellular uptake in hepatocytes and neurons. These changes show that the behaviour of particles in living organisms may differ considerably from what is observed in standard in vitro testing as the particles will behave differently in the different extracellular environment they are exposed to, highlighting one of the challenges of translating in vitro studies for nanoparticles to regulatory frameworks.
\end{abstract}

Keywords: Silver, Nanoparticle, Cytotoxicity, Stability, Spectroscopy

\section{Introduction}

Silver nanoparticles are used in a wide array of commercial products that can ultimately lead to human exposure [1-3]. They are also being developed as diagnostic biomedical contrast agents and nanoscale delivery vehicles for a wide array of applications including imaging and drug delivery to the brain [4-6]. Silver nanoparticles have well established antimicrobial properties [7-10] and have shown antiviral activity in some studies [4,11-14]. There is currently a great need to better understand the underlying mechanisms of how silver nanoparticles interact with biological environmentsin order to facilitate their safe use in protective equipment and other healthcare products. Understanding how particles behave in vivo is challenging and most in vitro data tests particles in standard cell culture medium that is supplemented with fetal bovine serum [15]. Attempts to compensate for particle dynamics, for example, measuring sedimentation, have been attempted, however, such models fail to appreciate the complexities of the systems [16]. Nanoparticles will sediment at vastly different rates depending on their concentration, the components of the media, the media concentration and the specific properties of the nanomaterial. It is impractical to measure sedimentation at each does in a toxicity curve, and changes in volume from a 96 well plate may perturb the kinetics. The does will also change over time, as will the cellular response. Aggregated nanoparticles also may not contribute to dose in the same way as non-aggregated particles, changing the route of uptake, or removing them entirely from the bioavailable pool.

Silver nanoparticles are particularly sensitive to their aqueous environment, and thus the composition of the medium plays a critical role in the transport and stability of the particles, ultimately affecting their bioavailability or targeted uptake [17-25]. We have previously noted that particles treated with human serum albumin are more stable than those coated with bovine serum albumin, the most abundant proteins in sera [26]. We have also shown that the size dependent stability of silver particles changes in media supplemented with human serum [27]. Here we have tested how commercial particles with different coatings behave in media with human proteins and biomolecules as opposed to those from fetal bovine serum, how the particles evolve over time and how that affects their uptake and cytotoxicty. While cells are typically grown in media with FBS, they can be grown equally well in media with HS and so we sought to measure the outcome of this serum substitution in order to develop a more 'humanized' assay to better model one component of the cytotoxicity assays toward in vivo conditions.

\section{Materials and Methods}

\section{Materials}

Silver nanoparticles were purchased from Nanocomposix as aqueous suspensions. $40 \mathrm{~nm}$ particle coatings included polyvinylpyrrolidone (PVP), branched polyethylimine (BPEI), polyethylene glycol (PEG), lipoic acid and citrate. Sizes were validated by UV-Vis and DLS and data were compared to those supplied by Nanocomposix for the specific batch numbers.

\section{Cell Culture}

SH-SY5Y and HepG2 cells (American Tissue Culture Center) were all grown in Dulbecco's modified Eagle's medium (DMEM) (Gibco) supplemented with 10\% Human AB serum (HS) (Sigma) and $1 \%$ penicillin-streptomycin (Pen/strep) $(50 \mu \mathrm{g} / \mathrm{ml}$, Gibco) unless stated otherwise and under standard culture conditions $\left(37^{\circ} \mathrm{C}, 5 \%\right.$ 
$\mathrm{CO}_{2}$ ). Media was filtered through $0.2 \mu \mathrm{m}$ filters after the addition of HS to remove any precipitates from the media. Cells were grown in T75 flasks (Falcon) and Trypsin-EDTA solution (Gibco) was used for passaging cells ( $3 \mathrm{~mL}$ per T75 flask for HepG2 and $2 \mathrm{~mL}$ for SHSY5Y). For passaging, SH-SY5Y cells were treated with Trypsin-EDTA at room temperature for $5 \mathrm{~min}$, while HepG2 cells were incubated for 10 minutes at 37 degrees.

\section{Ultraviolet-Visible (UV-Vis) Spectroscopy}

Samples were run on a Varian Cary $5000 \mathrm{UV}$-Vis spectrometer at ambient temperature under a nitrogen atmosphere using plastic (Brand) cuvettes with a $1 \mathrm{~mL}$ sampling volume. Samples for time courses were prepared as 1:1 mixtures of DMEM (no phenol red, Gibco) with $10 \% \mathrm{HS}$ and $1 \%$ penicillin-streptomycin and silver particles suspended in water at $20 \mu \mathrm{g} / \mathrm{mL}$. This results in a final concentration of $5 \% \mathrm{HS}$ and $10 \mu \mathrm{g} / \mathrm{mL}$ silver nanoparticle, a media mixture consistent with what was used for the cytotoxicity assays. At each time point a background of water/media without particles was measured to normalize any drift that might arise from the media changing over time.

\section{Dynamic Light Scattering (DLS)}

Samples were run on a Malvern Zetasizer Nano-ZS. Samples were run in plastic cuvettes (BRAND) with a $1 \mathrm{~mL}$ sample volume. Each sample was measured 5 times. All initial values for particles were consistent with manufactures specifications for the particles. Samples for time courses were prepared as 1:1 mixtures of DMEM (no phenol red) with $10 \% \mathrm{HS}$ and $1 \%$ penicillin-streptomycin and silver particles suspended in water at $20 \mu \mathrm{g} / \mathrm{mL}$. This results in a final concentration of $5 \% \mathrm{FBS}$ and $10 \mu \mathrm{g} / \mathrm{mL}$ silver nanoparticle.

\section{3-(4,5-Dimethylthiazol-2-yl)-2,5-Diphenyltetrazolium Bromide (MTT) Assay}

Cells were seeded into wells in a 96-well plate (Falcon) $\left(1 \times 10^{5}\right.$ cells $/ \mathrm{ml}, 100 \mu \mathrm{l}$ per well) to cover a 9 x 6 grid, filling 54 wells. Remaining wells were filled with $200 \mu \mathrm{l}$ of PBS. After 24 hours, $100 \mu \mathrm{l}$ volumes of dilutions of particles in water spanning from $20 \mu \mathrm{g} / \mathrm{mL}$ to $0.1 \mu \mathrm{g} /$ $\mathrm{mL}$ were added to the seeded wells (final concentrations spanning 10 $\mu \mathrm{g} / \mathrm{mL}$ to $0.05 \mu \mathrm{g} / \mathrm{mL}$ ). For each nanoparticle, eight dilutions were prepared and for each dilution six replicates were performed. In the remaining 6 wells, $100 \mu \mathrm{L}$ of water was added as a particle-free control. Cells were then incubated with nanoparticles for $72 \mathrm{~h}$. After $72 \mathrm{~h}, 50$ $\mu \mathrm{L}$ of a PBS solution of MTT $(2.5 \mathrm{mg} / \mathrm{ml})$ was added to each well and then incubated for $3 \mathrm{~h}$. After $3 \mathrm{~h}$, media was aspirated from all wells, leaving purple formazan crystals in those wells with viable cells. To each well, $150 \mu \mathrm{l}$ of DMSO was added. Plates were then agitated for 30 $\mathrm{s}$ to dissolve the crystals and analyzed using a plate reader (Fluorstar Omega, BMG Labtech.) to determine the absorbance of each well at $570 \mathrm{~nm}$. This reading divided by the average from the reading of the six control wells was plotted to determine the $\mathrm{IC}_{50}$ value of each complex for each cell line. Six replicates were performed for each sample on each cell line for each experiment, and each experiment was repeated three times. The values and errors reported are calculated from 18 unique measurements after curves were fit with a 4 -variable sigmoidal curve to calculate the $\mathrm{IC}_{50}$ values

\section{Metal Analysis}

To determine the AgNP uptake into each cell line, $5 \mathrm{~mL}$ cell suspensions of $10^{5}$ cells $/ \mathrm{mL}$ cells were plated into $3 \mathrm{~cm}$ Petri dishes. After $24 \mathrm{~h}, 250 \mu \mathrm{L}$ of nanoparticles (stock suspensions of $20 \mu \mathrm{g} / \mathrm{mL}$ ) were added to the cells. These samples were incubated for $24 \mathrm{~h}$, at which times the media was removed and the cells rinsed twice with PBS. Trypsin-EDTA ( $2 \mathrm{~mL}$ of $0.25 \%$ ) was then added to detach the cells from the plate surface, and an additional $3 \mathrm{~mL}$ of PBS added to resuspend the cells. These suspensions were transferred to 15 $\mathrm{mL}$ conical Falcon tubes and centrifuged for $5 \mathrm{~min}$ at $800 \mathrm{rpm}$. The supernatant was discarded and the cells resuspended and rinsed twice with PBS in this manner to remove particles from the cell surface. Cell pellets were then resuspended in $2 \mathrm{~mL}$ of PBS and counted using a LUNA automated cell counter (Logos Biosystems). Cell suspension ranged between 1 to $2 \times 10^{6}$ cells per sample for HepG2 cells and between 0.5 and $1.5 \times 10^{6}$ cells per sample for SH-SY5Y cells. After counting the cells in each sample, the cells were centrifuged again for $5 \mathrm{~min}$ at $2000 \mathrm{rpm}$ and the supernatant discarded. The cell pellet was dried overnight. To each dried pellet, $100 \mu \mathrm{L}$ of concentrated nitric acid was added and the sample left for $24 \mathrm{~h}$ to be digested. Samples were then diluted with $\mathrm{H}_{2} \mathrm{O}$ and submitted for ICP-MS (Element XR, Thermo Fisher Scientific, Bremen, Germany) analysis to determine the silver content. The results were then normalized to the number of cells in each sample. Each experiment was repeated 3 times and the values and errors reported are the average of these 3 measurements. Samples for residual silver ion content were prepared by centrifuging samples at $30 \mathrm{k} \mathrm{rpm}$ for 30 minutes. An aliquot for the top of the supernatant was removed and measured for silver content.

\section{Results and Discussion}

\section{Particle Dynamics in Cell Culture Media}

The silver nanoparticles are all stable in water and show now variation by UV-Vis or DLS over 72 hours. We have previously shown; however, that the spectra of particles do change over time and that the coating on the nanoparticles plays a role in determining how fast and in what manner the particles change over time in media with FBS [28]. The particles are mixed as a 1:1 mixture of the nanoparticle stock solution $(20 \mu \mathrm{g} / \mathrm{ml})$ and DMEM containing $1 \%$ pen/strep and $10 \%$ HS with spectral measurements made at 0,1 , $3,24,48$, and 72 hours. In all five cases, the spectra of the particles in media with HS shows significant differences over time compared to those for particles in media with FBS. Generally, if the spectra maxima shift left or right, this is indicative of the particle shrinking in size (dissolving) or growing in size (agglomerating or seeding from dissolved ions), respectively. Decreases in the absorption maximum indicate agglomeration that has led to the particles settling out of suspension and increases may be the result of a change in the shape of the particle [26]. The data for the particles in media with FBS has been previously published; [28] however, data from the spectra are included in Table 1 for comparison. For citrate particles (Table 1 and Figure 1) the peak maximum of the spectrum decreased much more rapidly between 3 and 24 hours than it did in media supplemented with FBS; however, the total shift of the peak was less, suggesting that particles were aggregating and precipitating from the media. This 
David Kennedy (2020) Coated Silver Nanoparticles Exhibit Unique Stability and Cytotoxicity in Media with Human Serum.

Table 1: Summary of the observed plasmonic absorption maxima for commercially tested $40 \mathrm{~nm}$ silver nanoparticles in media supplemented with human serum compared to media supplemented with fetal bovine serum. Data in FBS has been previously reported and is included here for comparison [28].

\begin{tabular}{|l|c|c|c|c|c|c|}
\hline \multirow{2}{*}{ Sample } & \multicolumn{3}{|c|}{ In HS } & \multicolumn{3}{|c|}{ In FBS } \\
\cline { 2 - 7 } & Initial $\boldsymbol{\lambda}_{\max }(\mathbf{n m})$ & $\mathbf{7 2}$ hour $\boldsymbol{\lambda}_{\max }(\mathbf{n m})$ & $\Delta \boldsymbol{\lambda}_{\max }(\mathbf{n m})$ & Initial $\boldsymbol{\lambda}_{\max }(\mathbf{n m})$ & $\mathbf{7 2} \mathbf{h o u r} \boldsymbol{\lambda}_{\max }(\mathbf{n m})$ & $\Delta \boldsymbol{\lambda}_{\max }(\mathbf{n m})$ \\
\hline $40 \mathrm{~nm}$ citrate & 424 & 424 & 0 & 423 & 428 & 429 \\
\hline $40 \mathrm{~nm}$ PVP & 420 & 424 & 4 & 416 & 442 & 13 \\
\hline $40 \mathrm{~nm}$ BPEI & 422 & 421 & 1 & 422 & 410 & 20 \\
\hline $40 \mathrm{~nm}$ PEG & 409 & 413 & 4 & 413 & 43 & 3 \\
\hline $40 \mathrm{~nm}$ lipoic acid & 434 & 434 & 0 & 421 & 4 & 15 \\
\hline
\end{tabular}
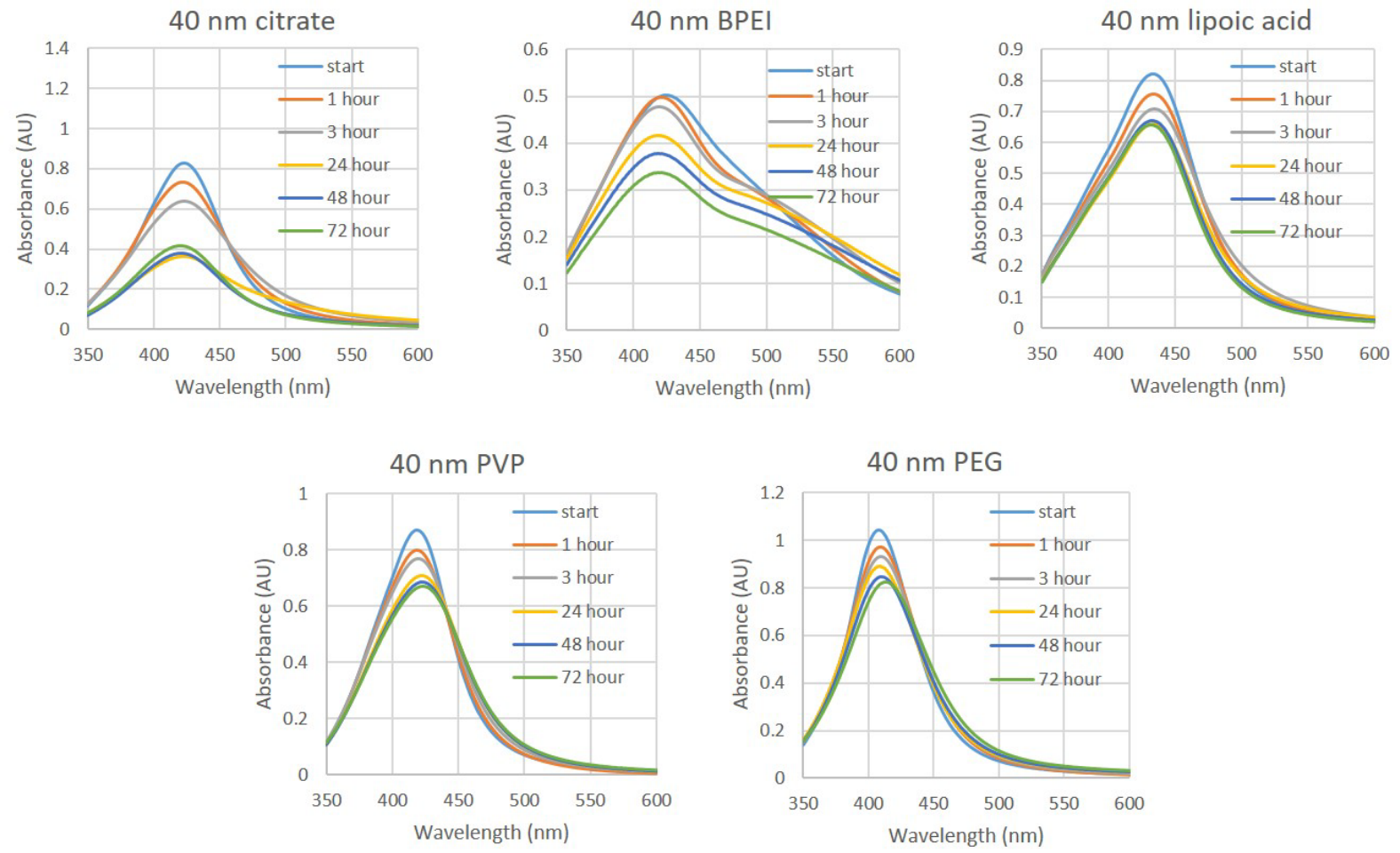

Figure 1: UV-Vis spectra of $40 \mathrm{~nm}$ silver nanoparticles with different surface coatings and functional groups recorded in cell culture media with a final concentration of $5 \%$ human male $\mathrm{AB}$ serum and $0.5 \%$ PEN/STREP. Spectra were recorded immediately upon mixing and then at 1, 3, 24, 48 and $72 \mathrm{~h}$.

was observable by eye as a thin red film slowly formed on the bottom of the cuvette. Similarly, for PVP coated particles, the maximum of the spectrum decreased more rapidly from 3 to 24 hours. In media with HS, the intensity of the maximum also continued to drop over the entire time course, whereas in FBS there was an increase in peak intensity after 48 hours. For PEG coated particles, the spectral maximum in media with HS shifted $4 \mathrm{~nm}$ to longer wavelength over 72 hours, while in media with FBS it shifted $3 \mathrm{~nm}$ in the opposite direction after 72 hours. For lipoic acid functionalized particles, there is no change in the position of the absorbance maximum, while in media with FBS there was a significant shift to longer wavelength of $15 \mathrm{~nm}$ over the same time frame. Finally for the BPEI coated particles, the immediate change observed in media with FBS is not observed here, and instead a much slower decrease in the spectral intensity is observed over the entire 72 hour time course. From all of these spectral analyses, it is clear that not only are the particles behaving differently in media with HS, but that each particle is behaving uniquely, not following any specific trend that can be applied to all particles when the type of serum is changed.

We then used DLS to further characterize changes to the size of the particles in the particle media suspensions over time (Table 2). Here, DLS measurements were made every 24 hours for 72 hours. Like with the UV-Vis spectra, the DLS data over time also shows different behaviour of the particles in media with HS compared to what we have previously reported in media with FBS [28]. For both citrate and PVP stabilized particles, the measured hydrodynamic diameter increased significantly over the first 24 hours, then decreased again, while in media with FBS the measured hydrodynamic diameter remained relatively constant throughout the 72 hour time course. For the BPEI stabilized particles, the initial measured diameter was now $50 \%$ greater than it was in FBS and decreased after 24 hours, whereas in FBS the particles continued to increase in size throughout the time course. Like for the PVP and citrate coated particles, the lipoic acid coated particles also increased in size at 24 hours, while only the PEG 
Table 2: Z-average hydrodynamic diameter as measured by DLS for commercially tested $40 \mathrm{~nm}$ silver nanoparticles in media supplemented with human serum Data is listed as average hydrodynamic diameter (standard error)/PDI value (standard error).

\begin{tabular}{|c|c|c|c|c|}
\hline Sample & Initial diameter $(\mathbf{n m}) /$ PDI & 24 hour diameter $(\mathrm{nm}) / \mathrm{PDI}$ & 48 hour diameter $(\mathrm{nm}) / \mathrm{PDI}$ & 72 hour diameter $(\mathrm{nm}) / \mathrm{PDI}$ \\
\hline $40 \mathrm{~nm}$ citrate & $50(2) / 0.56(0.03)$ & $47.9(0.8) / 0.57(0.01)$ & $50.2(0.4) / 0.55(0.05)$ & $48.9(0.6) / 0.54(0.03)$ \\
\hline 40 nm PVP & $63(1) / 0.46(0.01)$ & $61(2) / 0.47(0.01)$ & $52(01) / 0.45(0.03)$ & $50(2) / 0.44(0.02)$ \\
\hline $40 \mathrm{~nm}$ BPEI & $114.5(0.8) / 0.26(0.01)$ & $141(3) / 0.6(0.1)$ & $76.5(0.7) / 0.42(0.02)$ & $68.1(0.4) / 0.36(0.03)$ \\
\hline $40 \mathrm{~nm}$ PEG & $133(2) / 0.18(0.01)$ & $203(9) / 0.6(0.1)$ & $96.2(0.9) / 0.45(0.02)$ & $85(3) / 0.40(0.05)$ \\
\hline $40 \mathrm{~nm}$ lipoic acid & $89.9(0.9) / 0.19(0.01)$ & $143(5) / 0.44(0.01)$ & $100(1) / 0.25(0.01)$ & $91(2) / 0.26(0.01)$ \\
\hline
\end{tabular}

functionalized particles showed similar behaviour in both media. While this seems incompatible with the UV-Vis data, we can assume that the small changes in the spectral maximum of the PEG particles over time measured by UV-Vis and small decreases in size measured by DLS indicate small rearrangements at the particle surface interface with media components and highlight the complexity of quantifying changes to particles in cell culture media when so many components can interact at the particle-media interface. For 3 of the particles coatings, there is a significant change in the measured particle hydrodynamic diameters over the time course compared to data for particles in media with FBS suggesting that the particles age differently in this media and that greater levels of agglomeration likely occur from interactions with media components that do not occur in media with FBS, and that from the UV-Vis data this seems to occur generally within the first 24 hours after introduction of the particles to the media.

\section{Toxicity of AgNPs}

Toxicity of the nanoparticles was measured by an MTT assay in HepG2 and SH-SY5Y cells. We have previously shown that this assay is a reliable and highly reproducible assay for measuring the cytotoxicity of silver nanoparticles in these cell lines and continued to use these cell lines because of the high levels of nanoparticles that end up in the liver after exposure to circulation, and the known persistence of silver nanoparticles in the brain after prolonged or targeted exposure $[29,30]$. Silver nanoparticles are also affective anti-microbial agents [6,7,9,31-34] and their use to fight infection could be improved by understanding how to modulate their uptake by and toxicity to human cells via modified surface chemistry while still retaining their antimicrobial activity.

Again, cells are grown in media with HS and particles are tested in this media, to better understand how particles modified by HS exposure behave differently in in vitro assays (Table 3). In HepG2 cells, all of the particles are significantly more toxic compared to

Table 3: $\mathrm{IC}_{50}$ values using an MTT assay for $40 \mathrm{~nm}$ silver nanoparticles with different surface coatings in two cell lines after $72 \mathrm{~h}$ and are reported in $\mu \mathrm{g}$ silver/mL in media supplemented with human serum compared to media supplemented with fetal bovine serum which has been previously reported [28]. For $\mathrm{AgNO}_{3}$ the $\mathrm{IC}_{50}$ value is reported in $\mu$ moles/L.

\begin{tabular}{|l|c|c|c|c|}
\hline \multirow{2}{*}{ Sample } & \multicolumn{2}{|c|}{ In HS } & \multicolumn{2}{c|}{ In FBS } \\
\cline { 2 - 5 } & HepG2 & SH-SY5Y & HepG2 & SH-SY5Y \\
\hline $40 \mathrm{~nm}$ citrate & $0.8 \pm 0.2$ & $1.2 \pm 0.3$ & $1.8 \pm 0.2$ & $4.2 \pm 0.3$ \\
\hline $40 \mathrm{~nm}$ PVP & $0.9 \pm 0.2$ & $1.7 \pm 0.2$ & $1.8 \pm 0.2$ & $1.7 \pm 0.2$ \\
\hline $40 \mathrm{~nm}$ BPEI & $0.9 \pm 0.3$ & $0.5 \pm 0.2$ & $1.3 \pm 0.2$ & $2.5 \pm 0.2$ \\
\hline $40 \mathrm{~nm}$ PEG & $1.0 \pm 0.3$ & $5.0 \pm 0.4$ & $1.6 \pm 0.2$ & $1.8 \pm 0.2$ \\
\hline $40 \mathrm{~nm}$ lipoic acid & $1.6 \pm 0.3$ & $1.3 \pm 0.3$ & $1.2 \pm 0.2$ & $1.6 \pm 0.2$ \\
\hline $\mathrm{AgNO}_{3}$ & $3.5(0.2)$ & $4.8(0.3)$ & $3.7(0.2)$ & $3.2(0.2)$ \\
\hline
\end{tabular}

when exposed in media with FBS except for the particles coated with lipoic acid which are slightly less toxic. The $\mathrm{IC}_{50}$ values for the PVP and citrate stabilized particles are lower by a factor of two showing a very significant increase in cytotoxicity against this cell line under these conditions. The values in the SH-SY5Y cells are less consistent. Very significant increases in toxicity are observed for the citrate and BPEI stabilized particles, while changes for the PVP and lipoic acid stabilized particles are about the same, and the PEG stabilized particles are significantly less toxic under these conditions. These changes highlight the need to carefully interpret in vitro toxicity data as the choice of media and cell line can skew the measured results raising or diminishing the potential threat posed by exposure to the particles. And changes in how particles agglomerate under specific media conditions may contribute to their rate of endocytosis into cells. There is clearly a need for better in vitro testing methods and a broad selection of both cell lines and media conditions to better mimic in vivo conditions, as the nanoparticles are highly susceptible to subtle changes in their immediate aqueous environment.

\section{Uptake of AgNPs by Cells}

We next sought to determine if the changes in cytotoxicity data with media with HS could be correlated to changes in particle uptake that may arise from their different stability dynamics that we measured in media with HS (Table 4). In HepG2 cells there is little change in the measured silver in the cells when exposed to the same concentration of PVP, PEG and lipoic acid stabilized particles for the same time in media with HS as with FBS. This seems to counter the notion that the bioavailability of these particles is changing. For the BPEI particle, there is a small increase in the amount of measured silver, and for the citrate particles, a considerable decrease. For the citrate stabilized particles this is particularly odd as the decrease in uptake correlates with an increase in toxicity as opposed to the opposite as we expected. Centrifugation of the media was performed to attempt to measure changes in dissolved silver in the media by removing the particles and proteins in the media, but this did not indicate any difference

Table 4: Metal uptake analysis was performed on cell pellets treated with $40 \mathrm{~nm}$ silver nanoparticles with different coatings for $24 \mathrm{~h}$ in media supplemented with human serum compared to media supplemented with fetal bovine serum which have been previously reported [28]. Values reported are in ng silver $/ 10^{6}$ cells.

\begin{tabular}{|l|c|c|c|c|}
\hline \multirow{2}{*}{ Sample } & \multicolumn{2}{|c|}{ In HS } & \multicolumn{2}{c|}{ In FBS } \\
\cline { 2 - 5 } & HepG2 & SH-SY5Y & HepG2 & SH-SY5Y \\
\hline $40 \mathrm{~nm}$ citrate & $12 \pm 2$ & $3 \pm 1$ & $40 \pm 6$ & $63 \pm 8$ \\
\hline $40 \mathrm{~nm}$ PVP & $30 \pm 3$ & $3 \pm 1$ & $43 \pm 7$ & $28 \pm 6$ \\
\hline $40 \mathrm{~nm}$ BPEI & $55 \pm 6$ & $221 \pm 10$ & $32 \pm 5$ & $190 \pm 10$ \\
\hline $40 \mathrm{~nm}$ PEG & $31 \pm 3$ & $3 \pm 1$ & $30 \pm 5$ & $170 \pm 10$ \\
\hline $40 \mathrm{~nm}$ lipoic acid & $35 \pm 4$ & $7 \pm 2$ & $31 \pm 5$ & $25 \pm 6$ \\
\hline
\end{tabular}


in dissolved silver content between FBS and HS media; however, it is possible that the dissolved silver is more bio-available through coordination to species unique to HS that enhance their cytotoxicity. This argument, however, is countered by the fact that cytotoxicity of silver nitrate does not change in media with HS against HepG2 cells and the $\mathrm{IC}_{50}$ actually increases against SH-SY5Y cells compared to the $\mathrm{IC}_{50}$ values measured in media with FBS. It is clear that further investigation in required to understand why lower accumulated doses of silver under these exposure conditions are resulting in an increase in the measured cytotoxicity.

In SH-SY5Y cells, there is nearly an order of magnitude less silver measured in the cells when using media with HS compared to media with FBS. In the case of BPEI, the silver content is much higher, however, this appears to arise from precipitated large agglomerates that could not be separated from the harvested cells, even with repeated washes, and as such should not be counted as an intracellular accumulation of silver nanoparticles. Ignoring the data for BPEI then, it is also clear from the SH-SY5Y cell data, that there is not a direct correlation between cellular uptake and cytotoxicity. The measured value for BPEI coated particles does correlate with a very low $\mathrm{IC}_{50}$ value, and so we cannot say that there is not an increase in uptake that is driving this increase in toxicity, however, observing black particle agglomerates in the cell pellet suggests that the absolute value reported may not be a true reflection of the actual uptake into the cells. To clarify this we are now pursing various microscopic and single cell sorting techniques to quantify the silver content of the cells.

\section{Conclusion}

Assessing the safe use of nanoparticles is critical to the successful implementation of particles to the commercial market space. Measurement of silver nanoparticle cytotoxicity has been performed by several groups with mixed outcomes; however, it is clear that if the intended outcome is toxicity to human cells, then measuring particles under conditions that more closely mimic in vivo conditions is important. Changing the serum in cell culture media from FBS to Human male AB serum has a pronounced effect of the stability of silver nanoparticles, their uptake into cells and their cytotoxicity in HepG2 and SH-SY5Y cells. The increased toxicity does not correlate to uptake or to changes in dissolved silver ion content suggesting a more complex relationship between the particles and media components that are driving the cytotoxicity that is measured. As we continue to test nanoparticles for safety, it is critically important that we advance the quality of the in vitro tests performed and focus on building better models of the in vivo environment as any small changes can have a profound impact on the behaviour of nanoparticles and the myriad of interactions that can occur at their surfaces.

\section{References}

1. Benn T, Cavanagh B, Hristovski K, Posner JD, Westerhoff P (2010) The release of nanosilver from consumer products used in the home. J Environ Quality 39: 18751882. [crossref]

2. Calderon-Jimenez B, Johnson ME, Montoro Bustos AR, Murphy KE, Winchester MR, et al. (2017) Silver Nanoparticles: Technological Advances, Societal Impacts, and Metrological Challenges Front Chem 5: 6. [crossref]

3. Pourzahedi L, Vance M, Eckelman MJ (2017) Life Cycle Assessment and Release Studies for 15 Nanosilver-Enabled Consumer Products: Investigating Hotspots and Patterns of Contribution. Environ Sci Technol 51: 7148-7158.
4. Karunamuni R, Tsourkas A, Maidment AD (2014) Exploring silver as a contrast agent for contrast-enhanced dual-energy X-ray breast imaging. Brit J Radiol 87: 20140081. [crossref]

5. Liang P, Shi H, Zhu W, Gui Q, Ya X, et al. (2017) Oncotarget, Silver nanoparticles enhance the sensitivity of temozolomide on human glioma cells. Oncotarget 8: 75337539. [crossref]

6. Sotiriou GA, Pratsinis SE (2011) Engineering nanosilver as an antibacterial, biosensor and bioimaging material. Current opinion in chemical engineering 1: 3-10. [crossref]

7. Bhatia D, Mittal A, Malik DK (2016) Antimicrobial activity of PVP coated silver nanoparticles synthesized by Lysinibacillus varians. Biotech 6: 196 .

8. Hartemann P, Hoet P, Proykova A, Fernandes T, Baun A, et al. (2015) Nanosilver: Safety, health and environmental effects and role in antimicrobial resistance Mater Today 18: 122-123.

9. Hsueh YH, Lin KS, Ke WJ, Hsieh CT, Chiang CL, et al. (2015) The Antimicrobial Properties of Silver Nanoparticles in Bacillus subtilis Are Mediated by Released Ag+ Ions. PloS one 10: 0144306.

10. Niska K, Knap N, Kedzia A, Jaskiewicz M, Kamysz W, et al. (2016) Capping AgentDependent Toxicity and Antimicrobial Activity of Silver Nanoparticles: An In Vitro Study. Concerns about Potential Application in Dental Practice. Int J Med Sci 13: $772-782$

11. Mori Y, Ono T, Miyahira Y, Nguyen VQ, Matsui T, et al. (2013) Antiviral activity of silver nanoparticle/chitosan composites against $\mathrm{H} 1 \mathrm{~N} 1$ influenza A virus. Nanoscale research letters 8: 93.

12. Morris D, Ansar M, Speshock J, Ivanciuc T, Qu Y, et al. (2019) Antiviral and Immunomodulatory Activity of Silver Nanoparticles in Experimental RSV Infection. Viruses 11: 732. [crossref]

13. Orlowski P, Kowalczyk A, Tomaszewska E, Ranoszek-Soliwoda K, Wegrzyn A, et al. (2018) Antiviral Activity of Tannic Acid Modified Silver Nanoparticles: Potential to Activate Immune Response in Herpes Genitalis. Viruses 10: 524. [crossref]

14. Poon WL, Alenius H, Ndika J, Fortino V, Kolhinen V, et al. (2017) Nano-sized zinc oxide and silver, but not titanium dioxide, induce innate and adaptive immunity and antiviral response in differentiated THP-1 cells. Nanotoxicology 11: 936-951. [crossref]

15. Burdusel AC, Gherasim O, Grumezescu AM, Mogoanta L, Ficai A, et al. (2018) Biomedical Applications of Silver Nanoparticles: An Up-to-Date Overview. Nanomaterials 8: 681. [crossref]

16. DeLoid GM, Cohen JM, Pyrgiotakis G, Demokritou P (2017) Preparation, characterization, and in vitro dosimetry of dispersed, engineered nanomaterials. Nature Protocols 12: 355-371. [crossref]

17. Azimzada A, Tufenkji N, Wilkinson KJ (2017) Transformations of silver nanoparticles in wastewater effluents: links to Ag bioavailability. Environmental Science: Nano 4: 1339-1349.

18. Beer C, Foldbjerg R, Hayashi Y, Sutherland DS, Autrup H (2012) Toxicity of silver nanoparticles - nanoparticle or silver ion? Toxicology Letters 208: 286-292. [crossref]

19. Behra R, Sigg L, Clift MJD, Herzog F, Minghetti M, et al. (2013) Bioavailability of silver nanoparticles and ions: from a chemical and biochemical perspective. Journal of the Royal Society Interface 10: 20130396. [crossref]

20. Durán N, Silveira CP, Durán M, Martinez DST (2015) Silver nanoparticle protein corona and toxicity: a mini-review. Journal of Nanobiotechnology 13: 55. [crossref]

21. Guo X, Li Y, Yan J, Ingle T, Jones MY, et al. (2016) Size- and coating-dependent cytotoxicity and genotoxicity of silver nanoparticles evaluated using in vitro standard assays. Nanotoxicology 10: 1373-1384. [crossref]

22. Meier C, Voegelin A, Pradas del Real A, Sarret G, Mueller CR, et al. (2016) Transformation of Silver Nanoparticles in Sewage Sludge during Incineration. Environmental Science \& Technology 50: 3503-3510.

23. Molleman B, Hiemstra T (2017) Time, pH, and size dependency of silver nanoparticle dissolution: the road to equilibrium. Environmental Science: Nano 4: 1314-1327.

24. Sharma VK, Siskova KM, Zboril R, Gardea-Torresdey JL (2014) Organic-coated silver nanoparticles in biological and environmental conditions: Fate, stability and toxicity. Advances in Colloid and Interface Science 204: 15-34. [crossref] 
David Kennedy (2020) Coated Silver Nanoparticles Exhibit Unique Stability and Cytotoxicity in Media with Human Serum.

25. Tejamaya M, Romer I, Merrifield RC, Lead JR (2012) Stability of citrate, PVP, and PEG coated silver nanoparticles in ecotoxicology media. Environmental Science \& Technology 46: 7011-7017. [crossref]

26. Kennedy DC, Qian H, Gies V, Yang L (2018) Human serum albumin stabilizes aqueous silver nanoparticle suspensions and inhibits particle uptake by cells. Environmental Science: Nano 5: 863-867.

27. Kennedy DC, Gies V, Jezierski A, Yang L (2019) Effects of human serum on the stability and cytotoxicity of silver nanoparticles. SN Applied Sciences 1: 1510.

28. Kennedy DC, Gies V, Jezierski A, Yang L (2019) Changes in the physical properties of silver nanoparticles in cell culture media mediate cellular toxicity and uptake. Journal of Nanoparticle Research 21: 132.

29. Afifi M, Saddick S, Abu Zinada OA (2016) Toxicity of silver nanoparticles on the brain of Oreochromis niloticus and Tilapia zillii. Saudi Journal of Biological Sciences 23: 754-760.
30. Antsiferova A, Yu B, Demin V, Kashkarov P, Kovalchuk M, et al. (2015) Extremely low level of Ag nanoparticle excretion from mice brain in in vivo experiments. IOP Conference Series: Materials Science and Engineering 98: 012003.

31. Jung WK, Koo HC, Kim KW, Shin S, Kim SH, et al. (2008) Antibacterial Activity and Mechanism of Action of the Silver Ion in Staphylococcus aureus and Escherichia coli. Applied and Environmental Microbiology 74: 2171-2178. [crossref]

32. Le Ouay B, Stellacci F (2015) Antibacterial activity of silver nanoparticles: A surface science insight. Nano Today 10: 339-354.

33. Salomoni R, Léo P, Montemor AF, Rinaldi BG, Rodrigues M (2017) Antibacterial effect of silver nanoparticles in Pseudomonas aeruginosa. Nanotechnology science and applications 10: 115-121. [crossref]

34. Tang S, Zheng J (2018) Antibacterial Activity of Silver Nanoparticles: Structural Effects. Advanced healthcare materials 7: 1701503. [crossref] 